ИЗВЕСТИЯ АКАДЕМИИ НАУК ЭСТОНСКОИ ССР. ФИЗИКА * МАТЕМАТИКА

PROCEEDINGS OF THE ACADEMY OF SCIENCES OF THE ESTONIAN SSR. PHYSICS * MATHEMATICS

$1988,37, \quad 2$

\title{
EXCITED STATE DYNAMICS OF AMORPHOUS SYSTEMS AT LOW TEMPERATURE STUDIED BY HOLE-BURNING
}

\author{
(Presented by K. K. Rebane)
}

Contradictory results on optical dephasing of organic amorphous systems obtained by hole-burning and photon echoes are discussed. A systematic hole-burning study of pentacene in polymethylmethacrylate (PMMA) and resorufin in ethanol glass between $\sim 0.3$ and $4.2 \mathrm{~K}$, carried out in our laboratory, is presented. The results show that only the widths of the holes burnt at lowest laser fluences and probed in fluorescence reflect the homogeneous linewidths. A discussion on spectral diffusion processes follows. Finally, the effect of a magnetic field on holes burnt in zero field in an amorphous system (free-base porphin in polyethylene at $4.2 \mathrm{~K}$ ) is shown, and theoretically interpreted.

\section{Introduction}

Since it is difficult to cover, in half hour, the many applications of hole-burning on glasses at low temperature, I have chosen two subjects which, I think, fit into the context of this conference. The first one, especially, is much in fashion these days and a matter of disagreement and lively discussion: the apparent contradiction between photon echoes and hole-burning when applied to optical dephasing of organic amorphous systems. For it has recently been claimed $\left[{ }^{1,2}\right]$ that the hole-burning technique does not give information on the optical homogeneous linewidth $\Gamma_{\text {hom }}$. Slow spectral diffusion processes have been invoked as the reason for the alleged discrepancy between the results obtained by both techniques. Obviously many questions arise at this point: Is the difference between the linewidths measured by these techniques physically real? Are the time scales of the two experiments (picoseconds $\left.{ }^{2}\right]$ or microseconds [ $\left.{ }^{1}\right]$ for photon echoes, seconds to minutes for hole-burning) responsible for this difference? What are the conditions necessary for slow relaxation processes in the glass (spectral diffusion) that broaden the hole? We will try to give answers to these questions, using two examples which have been studied in a systematic way in our laboratory: pentacene in PMMA [ $\left.{ }^{3}\right]$ and resorufin in ethanol glass [ $\left.{ }^{4}\right]$.

The second subject I want to mention is the effect of a magnetic field on holes burnt in zero field in the $S_{1} \leftarrow S_{0} 0-0$ transition of an organic guest molecule randomly oriented in an amorphous host. We have chosen free-base porphin in polyethylene and have compared the Zeeman effect observed in this amorphous system $\left.{ }^{5}\right]$ with that previously observed for the same guest oriented in a single crystal of $n$-octane $\left[{ }^{6}\right]$. 


\section{Results and discussion}

Optical dephasing and spectral diffusion

Pentacene in polymethylmethacrylate (PMMA) $\left[{ }^{3}\right]$. It has been argued that systems undergoing non-photochemical hole-burning (NPHS) $\left.{ }^{7-9}\right]$ have large homogeneous linewidths $\Gamma_{\text {hom }}$ of the order of $\mathrm{cm}^{-1}$, and residual linewidths that correspond to ps-dephasing times at $T \rightarrow 0\left[{ }^{9-11}\right]$, with a temperature dependence of holewidths which is linear in some cases and quadratic in others. These results are in strong contrast with those found for amorphous organic systems that undergo photochemical hole-burning (PHB) $[12,13,14]$, for which much narrower holes of the order of a few 10-1000 MHz were observed and which extrapolate to, or almost reach, the lifetime-limited values of the guests $\Gamma_{0}=\left(2 \pi T_{1}\right)^{-1}$ when $T \rightarrow 0$ $\left[{ }^{15-20}\right]$. Furthermore, in these systems the value of $\Gamma_{\text {hom }}-\Gamma_{0}$ follows a $T^{1.3}$ temperature dependence at low temperatures down to $0.3 \mathrm{~K}$. Organic guest molecules that undergo PHB and were studied in our laboratory are represented in Fig. 1, whereas a few results on optical dephasing are shown in Fig. $2\left[{ }^{20}\right]$.
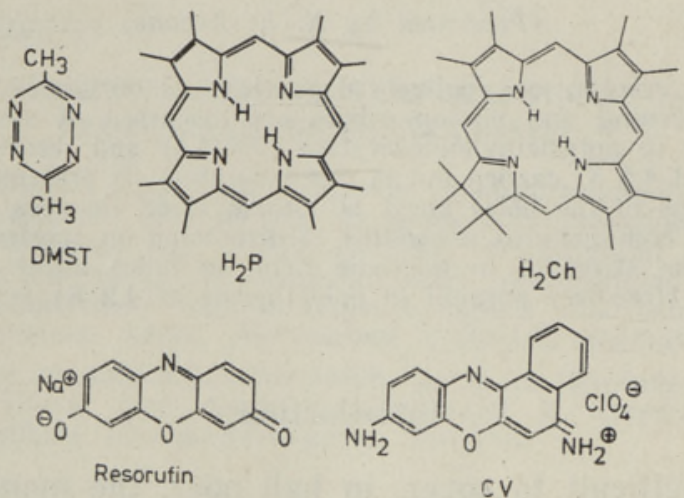

Fig. 1. Organic molecules studied as guests in amorphous hosts. They undergo photochemical hole-burning (PHB). Top: dimethyl-s-tetrazine (DMST), free-base porphin $\left(\mathrm{H}_{2} \mathrm{P}\right)$, free-base chlorin $\left(\mathrm{H}_{2} \mathrm{Ch}\right)$. Bottom: ionic dyes resorufin and cresylviolet $\left.(\mathrm{CV}){ }^{22}\right]$.
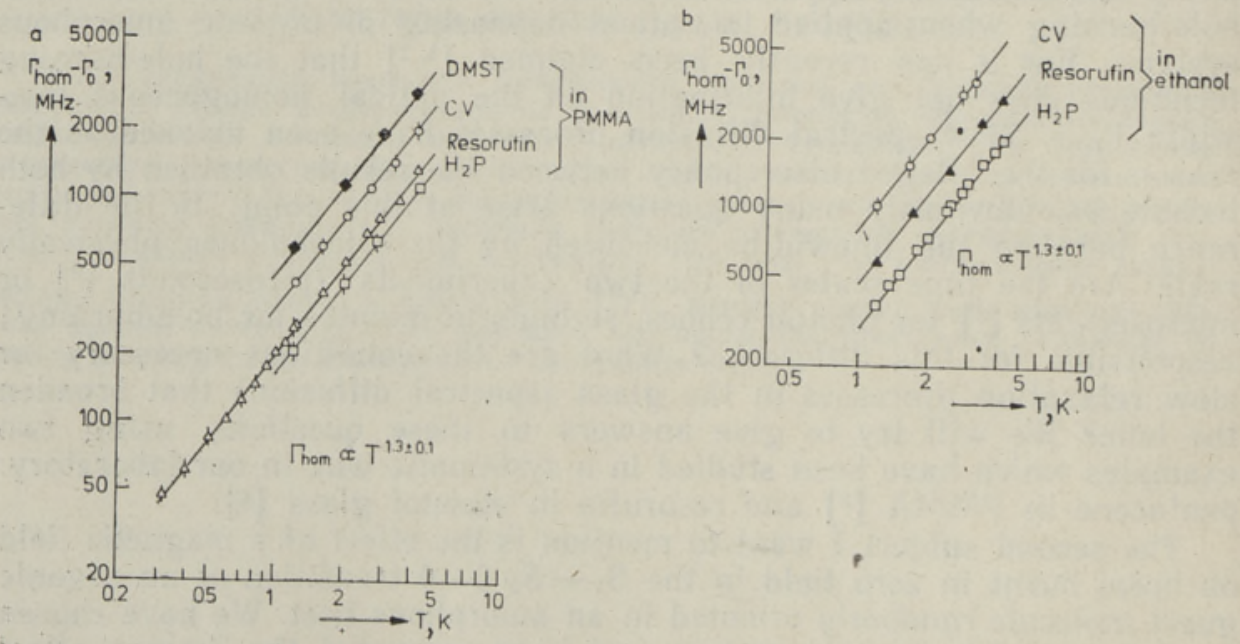

Fig. 2. Log-log plot of $\Gamma_{h o m}-\Gamma_{0}$ versus $T$ for: $a-$ dimethyl-s-tetrazine (DMST), cresylviolet $(\mathrm{CV})$, resorufin and free-base porphin $\left(\mathrm{H}_{2} \mathrm{P}\right)$ as guests in PMMA, $b-\mathrm{CV}$, resorufin and $\mathrm{H}_{2} \mathrm{P}$ in ethanol. All curves follow a $T^{1.3 \pm 0.1}$ dependence $\left[{ }^{20}\right]$. 
The difference in optical dephasing between NPHB- and PHB-systems has recently been stressed by L. W. Molenkamp and D. A. Wiersma [1] on the basis of a comparison of accumulated photon echo and holeburning results obtained for pentacene in PMMA. The linewidths measured by NPHB were much larger than those derived from photon echoes. Moreover, the temperature dependence of the holewidths was $T^{2}$, whereas that of photon echo linewidths was $T^{1.3}$ between 1.5 and $12 \mathrm{~K}$. This difference was attributed to «spectral diffusion» [1], as mentioned above.

We have re-investigated this system between 1.2 and $4.2 \mathrm{~K}$ and studied, in particular, the influence on the holewidth of laser power, burning time, sample preparation, optical density and sample heating $\left[{ }^{3}\right]$. The holes were burnt in the $S_{1} \leftarrow S_{0} 0-0$ transition of pentacene in PMMA at $\simeq 5820 \AA$. Two types of samples were used: thin films $(0.13 \mathrm{~mm})$ of optical density $O D \simeq 0.009$ prepared by mixing solutions of pentacene in toluene and PMMA in dichloromethane and pumping for 48 hours, and a thick piece $(2.2 \mathrm{~mm})$ of $O D \simeq 0.9$ prepared in a hydraulic press at $20{ }^{\circ} \mathrm{C}$ (the latter was given to us by the authors of $\left[{ }^{1}\right]$ ). The results of the homogeneous linewidth $\Gamma_{\text {hom }}^{\prime}\left(\Gamma_{\text {hom }}^{\prime}=1 / 2 \Gamma_{\text {hole }}\right.$ for hole-burning data and $\Gamma_{\text {hom }}^{\prime}=\left(\pi T_{2}\right)^{-1}$ for photon echo data $\left.\left[{ }^{1}\right]\right)$ as a function of temperature $T$ are plotted in Fig. 3 (lowest curve) in a log-log form, together with the NPHB and photon echo results of [ $\left.{ }^{1}\right]$ (dashed lines). We have observed no difference in holewidths in the two samples as long as the holes were probed in fluorescence. Notice that our hole-burning data, which yield much narrower holes (factor 7-20) than those of [1] and show a $T^{1.3}$ dependence, were obtained with very low burning fluences $P t \leqslant 7.5 \times$ $\times 10^{-3} \mathrm{~J} \cdot \mathrm{cm}^{-2}(P-$ laser power, $t$ - burning time $)\left[{ }^{3}\right]$. In contrast, the NPHB-data of ${ }^{[1]}$ were obtained by probing the holes in transmission

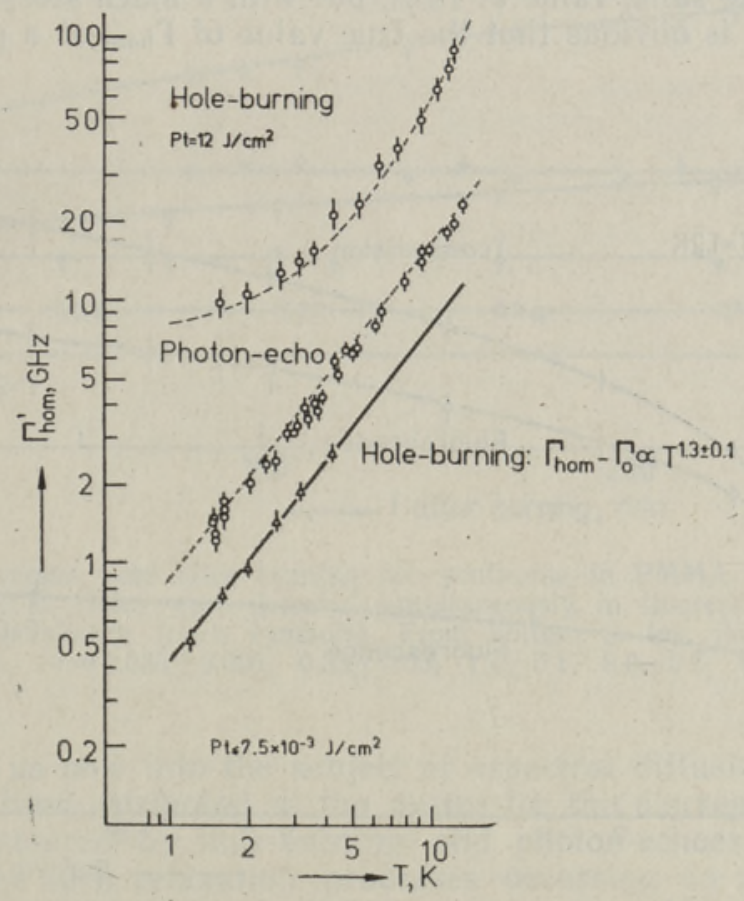

Fig. 3. Double-logarithmic plot of $\Gamma_{\text {hom }}^{\prime}$ vs. $T$ for pentacene in PMMA. ( $\Gamma_{\text {hom }}^{\prime}=1 / 2 \Gamma_{\text {hole }}$ for hole-burning data, and $\Gamma_{\text {hom }}^{\prime}=\left(\pi T_{2}\right)^{-1}$ for photon echo data [']). The two upper curves (dashed lines) are reproduced from [ $\left.{ }^{1}\right]$. The lowest curve represents our holeburning data for $P t \leqslant 7.5 \times 10^{-3} \mathrm{~J} \cdot \mathrm{cm}^{-2}\left[{ }^{3}\right]$. 
through the sample with values of $P t=12 \mathrm{~J} \cdot \mathrm{cm}^{-2}$. Notice, further, that the widths derived from accumulated photon echoes also follow a $T^{1.3}$ dependence, but are a factor of $\sim 2$ larger than our hole-burning values of $\Gamma_{\text {hom. }}$. This discrepancy may be due to various causes: the photon echoes were performed in a flow cryostat and the signals were measured in transmission with a rathèr high incident power $P \simeq 5 \mathrm{~W} \cdot \mathrm{cm}^{-2}$, which produces considerable energy dissipated in the bulk of the sample: It is known that glasses have poor thermal conductivity, as a consequence the temperature may have been higher than assumed in $\left.{ }^{1}\right]$.

The discrepancy between the NPHB results of $\left.{ }^{[1}\right]$ and ours $\left[{ }^{3}\right]$ may also be attributed to the same reasons, namely burning power and temperature, since the holes in $\left.{ }^{[1}\right]$ were probed in transmission at high fluences $\left(P=20 \mathrm{~mW} \cdot \mathrm{cm}^{-2}, t=10 \mathrm{~min}\right)$, and ours were probed in fluorescence at $10^{3}$ times lower fluences. Another cause is probably the holedetection technique. In [ ${ }^{1}$ ] holes were probed by scanning a monochromator (in combination with a lamp), as very often reported in literature $\left[{ }^{8-10,21}\right]$. In this way holes can be observed only if very high burning fluences are used. Furthermore, the resolution is then given by the slit of the monochromator $(\sim 3-20 \mathrm{GHz})$ instead of the bandwidth of the laser $(\sim 1-2 \mathrm{MHz})[3,19,20,22]$. Thus, neither the value of $\Gamma_{\text {hom }}^{\prime}$ nor the $T^{2}$ dependence of $\Gamma_{\text {hom }}^{\prime}$ in $\left.{ }^{1}{ }^{1}\right]$ are related to optical dephasing processes.

In order to get the true homogeneous linewidth $\Gamma_{\text {hom }}$, we have studied the holewidth dependence $1 / 2 \Gamma_{\text {hole }}$ on burning time for different burning powers, at $1.2 \mathrm{~K}$. The holes were detected simultaneously by monitoring the fluorescence signal and the transmission signal through the sample. This is shown in Fig. 4. Notice that the values of $1 / 2 \Gamma_{\text {hole }}$ on the lowest curve extrapolate to $\Gamma_{\text {hom }}=0.50 \mathrm{GHz}$ when $t \rightarrow 0$, whereas the two upper curves reach the same value of $\Gamma_{\text {hom }}$, but with a much steeper slope. From these results it is obvious that the true value of $\Gamma_{\text {hom }}$ at a given tempera-

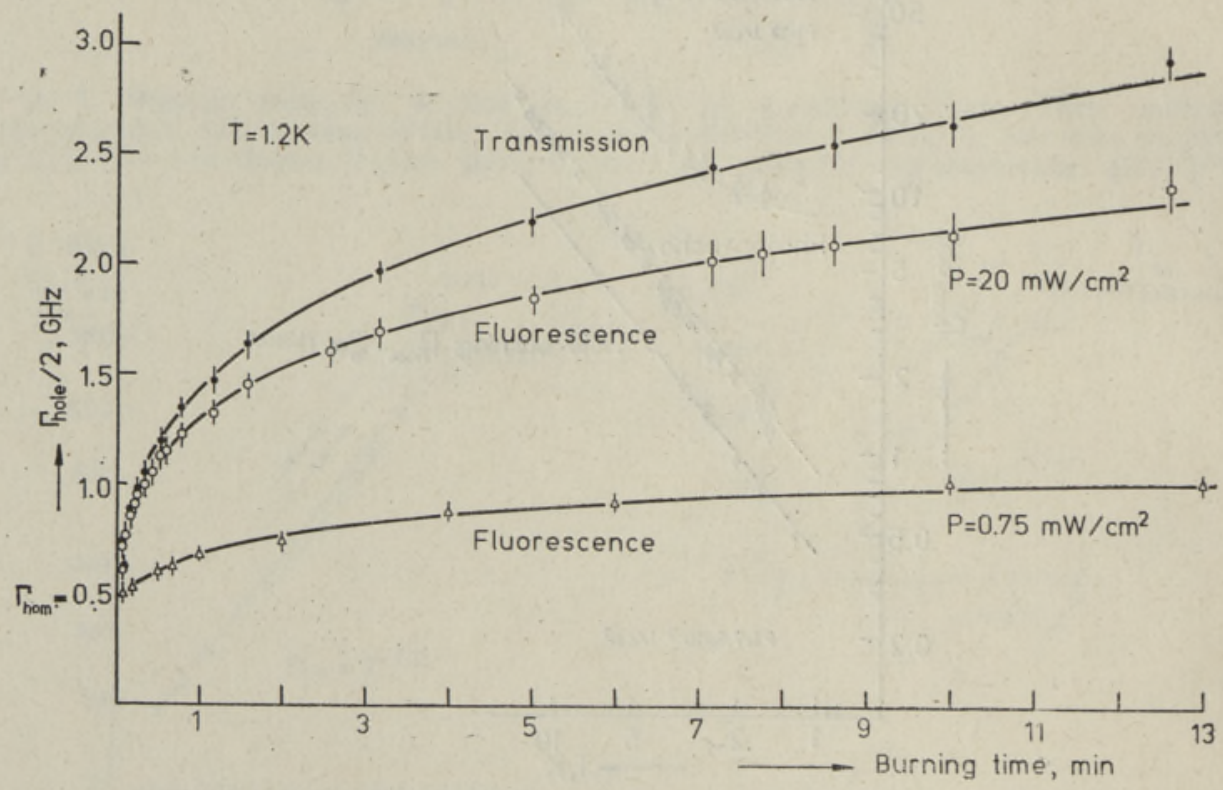

Fig. 4. $1 / 2 \Gamma_{\text {hole }}$ as a function of burning time for pentacene in PMMA at $T=1.2 \mathrm{~K}$, for two burning powers. At $P=20 \mathrm{~mW} \cdot \mathrm{cm}^{-2}$ holes were detected simultaneously via the fiuorescence excitation signal and the transmission signal through the sample. At $P=0.75 \mathrm{~mW} \cdot \mathrm{cm}^{-2}$ holes were observed in fluorescence only. For $t \rightarrow 0,1 / 2 \Gamma_{\text {hole }} \cong$ $\simeq \Gamma /$ hom $=0.50 \mathrm{GHz}\left[{ }^{3}\right]$. 
ture is only obtained at the lowest possible laser fluences (in this case, when $\left.P t \leqslant 20 \times 10^{-3} \mathrm{~J} \cdot \mathrm{cm}^{-2}\right)$. It should be noted that the holewidths probed in transmission could only be observed when $P t \geqslant 30 \times 10^{-3} \mathrm{~J} \cdot \mathrm{cm}^{-2}$, which shows that this detection method is not as sensitive as fluorescence excitation spectroscopy. Furthermore, the holes detected in transmission were generally broader than those detected in fluorescence, and they only coincide at very short burning times (in Fig. 4, at $t<10 \mathrm{~s}$ for $P=20 \mathrm{~mW} \cdot \mathrm{cm}^{-2}$ ). We attribute this difference in holewidth to laser heating of the bulk of the glassy sample (which is $2.2 \mathrm{~mm}$ thick and has an $O D \sim 0.9$ ). In contrast, holewidths probed in fluorescence arise from molecules at the surface of the sample, which are in thermal equilibrium with the liquid helium.

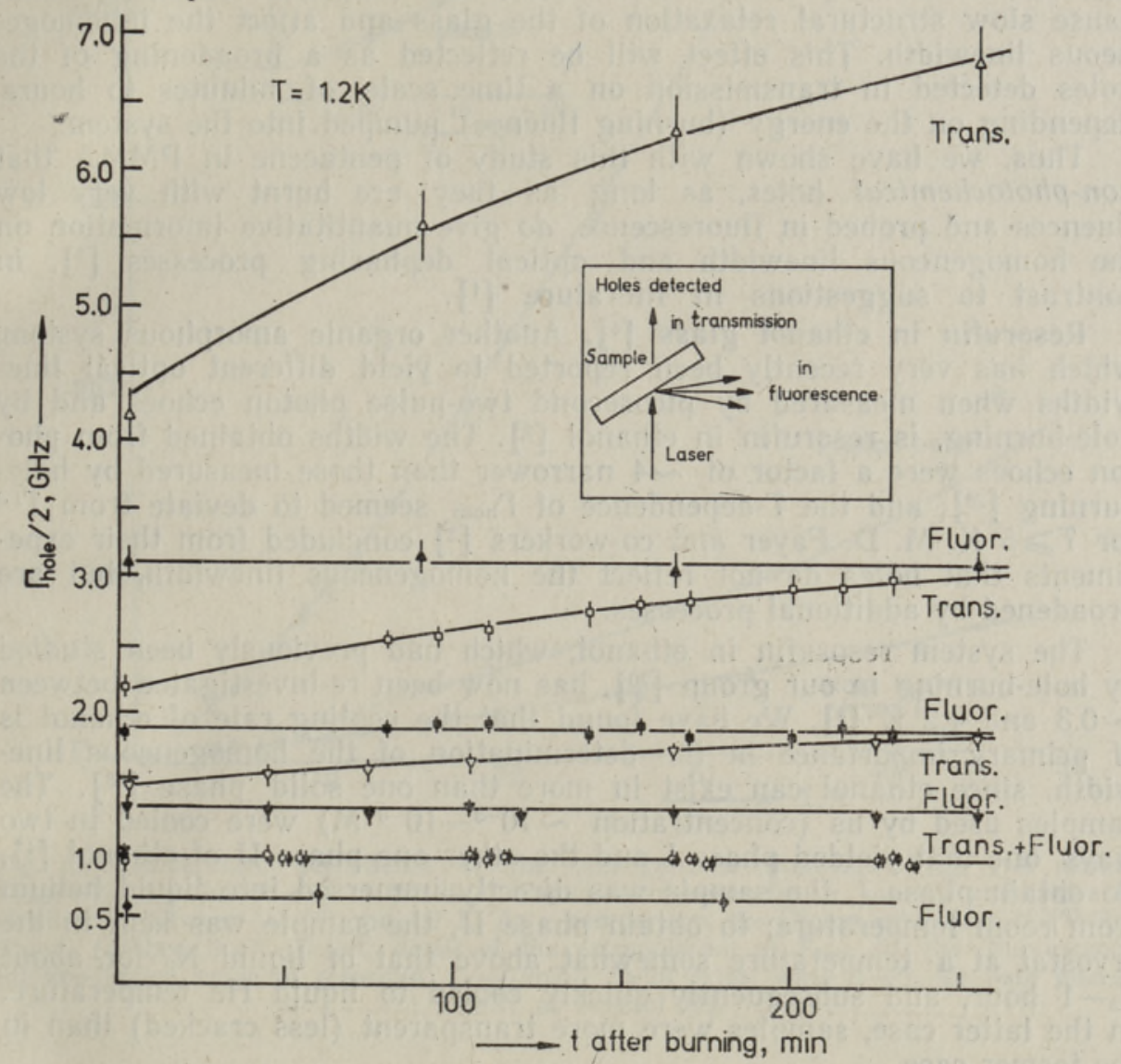

Fig. 5. $1 / 2 \Gamma_{\text {hole }}$ versus time after burning for pentacene in PMMA (sample of $O D=$ $=0.9)$ at $T=1.2 \mathrm{~K}$. Holes were detected simultaneously in fluorescence (closed symbols) and in transmission (open symbols). From bottom to top, increasing values of burning fluences: $P t=0.035 \pm 0.005,0.35 \pm 0.05,1.4 \pm 0.1,6.0 \pm 0,5,48 \pm 2 \mathrm{~J} \cdot \mathrm{cm}^{-2}\left[{ }^{3}\right]$.

This leads us now into the subject of «spectral diffusion» [21], a process that has been attributed as the source for the discrepancies between linewidths measured by hole-burning and photon-echoes $\left[{ }^{1}\right]$. We have shown $\left[{ }^{3}\right]$ that such relaxation processes occurring on a time scale of hours only take place under special experimental conditions. In Fig. 5 we have plotted $1 / 2 \Gamma_{\text {hole }}$ versus time after burning (defined as the time in the dark between burning and probing a hole) for pentacene in PMMA at $T=1.2 \mathrm{~K}$, for different burning fluences $\left[{ }^{3,22}\right]$. The holes were probed simultaneously in fluorescence (closed circles) and in transmission 
(open circles). It should be noticed that the former do not show any broadening as a function of time, not even at such large burning fluences as $P t=50 \mathrm{~J} \cdot \mathrm{cm}^{-2}$. The holes probed in transmission through the sample, and burnt at fluences above a given threshold (here, $P t \geqslant$ $\geqslant 1 \mathrm{~J} \mathrm{~cm}-2$, do undergo «spectral diffusion»: they broaden on a time scale of hours $(\tau \sim 220 \mathrm{~min})$. This effects is more visible for higher burning fluences (see upper curves in Fig. $5\left[{ }^{3}\right]$ ).

We think that molecules probed at the surface of the sample (holes detected in fluorescence) do not show spectral diffusion because they are in thermal contact with the liquid helium. Molecules probed in transmission, in contrast, are placed in the bulk of the sample which has poor thermal conductivity. In the latter case, heat may induce strains which cause slow structural relaxation of the glass and affect the inhomogeneous linewidth. This effect will be reflected as a broadening of the holes detected in transmission on a time scale of minutes to hours, depending on the energy (burning fluence) pumped into the system.

Thus, we have shown with this study of pentacene in PMMA that non-photochemical holes, as long as they are burnt with very low fluences and probed in fluorescence, do give quantitative information on the homogeneous linewidth and optical dephasing processes $\left[{ }^{3}\right]$, in contrast to suggestions in literature [ $\left.{ }^{1}\right]$.

Resorufin in ethanol glass [ $\left.{ }^{4}\right]$. Another organic amorphous system, which has very recently been reported to yield different optical linewidths when measured by picosecond two-pulse photon echoes and by hole-burning, is resorufin in ethanol $\left.{ }^{2}\right]$. The widths obtained from photon echoes were a factor of $\sim 4$ narrower than those measured by holeburning $\left[{ }^{20}\right]$, and the $T$-dependence of $\Gamma_{\text {hom }}$ seemed to deviate from $T^{1.3}$ for $T \geqslant 5$ K. M. D. Fayer and co-workers [ [2] concluded from their experiments that holes do not reflect the homogeneous linewidth, but are broadened by additional processes.

The system resorufin in ethanol, which had previously been studied by hole-burning in our group $\left[{ }^{20}\right]$, has now been re-investigated between $\sim 0.3$ and $4.2 \mathrm{~K}\left[{ }^{4}\right]$. We have found that the cooling rate of ethanol is of primary importance in the determination of the homogeneous linewidth, since ethanol can exist in more than one solid phase $\left[{ }^{23}\right]$. The samples used by us (concentration $\sim 10^{-3}-10^{-6} \mathrm{M}$ ) were cooled in two ways, one that yielded phase I and the other one phase II of ethanol [ $\left.{ }^{4}\right]$. To obtain phase I, the sample was directly immersed into liquid helium from room temperature; to obtain phase II, the sample was kept in the cryostat at a temperature somewhat above that of liquid $\mathrm{N}_{2}$ for about $1 / 2-1$ hour, and subsequently quickly cooled to liquid He temperature. In the latter case, samples were more transparent (less cracked) than in the former case.

Although most of the holes were burnt at $\sim 595 \mathrm{~nm}$ in the $S_{1} \leftarrow S_{0} 0-0$ transition of resorufin, we obtained the same widths for holes burnt up to $573 \mathrm{~nm}\left[{ }^{4}\right]$. The holewidths in the two phases of ethanol, however, are very different. Thus, care must be taken when ethanol is used as a host matrix for optical measurements. This is shown in Fig. 6 where $\Gamma_{\text {hom }}$ $\left(\Gamma_{\text {hom }}=1 / 2 \Gamma_{\text {hole }}\right.$ at burning fluence $\left.\rightarrow 0\right)$ has been plotted as a function of temperature between $\sim 0.3$ and $4.2 \mathrm{~K}$ for both phases of ethanol [ $\left.{ }^{4}\right]$. For comparison, the photon echo data of [ $\left.{ }^{2}\right]$ are also shown (dashed line). Notice that at a given temperature the values of $\Gamma_{\text {hom }}$ in the two phases differ by a factor of $\sim 8$, whereas the photon echo linewidths are $\sim 4$ times smaller than the hole-burning widths of resorufin in phase I $[2,4,20]$. The latter led to the statement in literature $\left[{ }^{2}\right]$ that hole-burning does not yield the homogeneous linewidth. However, the values of $\Gamma_{\text {hom }}$ for resorufin in phase II of ethanol [ $\left.{ }^{4}\right]$ are even smaller (by a factor of 


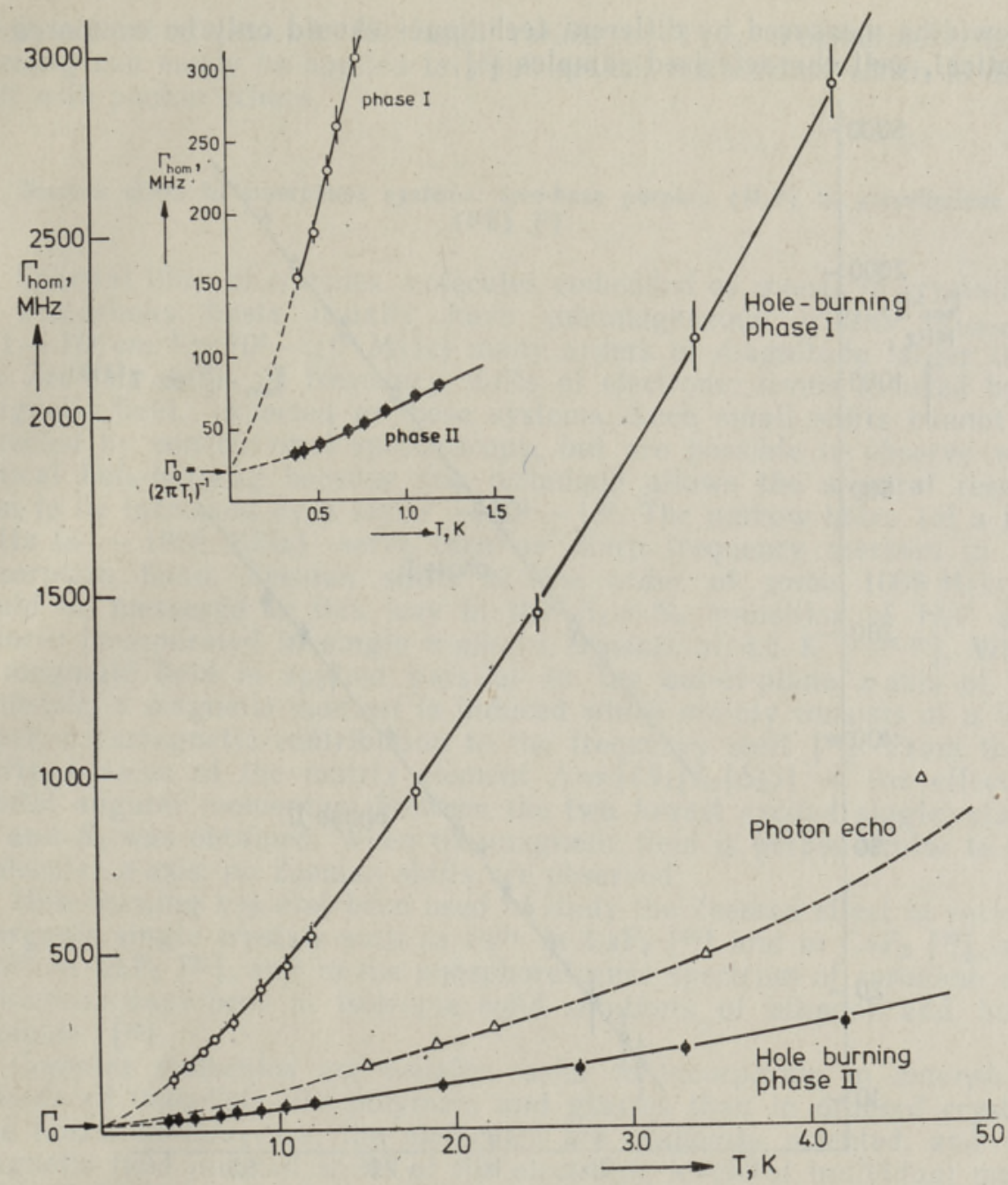

Fig. 6. Temperature dependence of the homogeneous linewidth $\Gamma_{\text {hom }}$ (we define $\Gamma_{\text {hom }}=1 / 2 \Gamma_{\text {hole }}$ for $P t \rightarrow 0$ ) of the $0-0$ transition of resorufin in phase I and phase II of ethanol, between $\sim 0.3$ and $4.2 \mathrm{~K}$. As a comparison, the photon echo data of $\left[{ }^{2}\right]$ are shown (dashed line). Insert: detail of the extrapolation of $\Gamma_{\text {hom }}$ to the fluorescence lifetime-limited value of resorufin, $\Gamma_{0}=\left(2 \pi T_{1}\right)^{-1} \simeq 20 \mathrm{MHz}$, when $T \rightarrow 0$, for both phases I and II of ethanol [4].

2) than those obtained by photon echoes. It should further be remarked that the values of $\Gamma_{\text {hom }}$ for both samples of resorufin in ethanol extrapolate to $\sim 20 \mathrm{MHz}$ (see insert of Fig. 6), which is in agreement with the fluorescence lifetime-limited value of the guest $\Gamma_{0}=\left(2 \pi T_{1}\right)^{-1}$ for $T \rightarrow 0\left[{ }^{20}\right]$.

We think that the photon echo data of $\left[{ }^{2}\right]$ were measured in the slowly cooled phase II of resorufin in ethanol (which has better optical quality than phase I). Thus we attribute the seeming discrepancy between the results obtained with the two techniques to differences in samples used. In order to prove the contrary, photon echoes should be measured in both phases of resorufin in ethanol. The discrepancy of a factor of $\sim 2$ between photon echoes and hole-burning in phase II may be due to high peak powers used in the ps two-pulse photon echo experiments which would cause non-linear optical effects or local heating of the sample. 
Linewidths measured by different techniques should only be compared in identical, well characterized samples [ $\left.{ }^{4}\right]$.

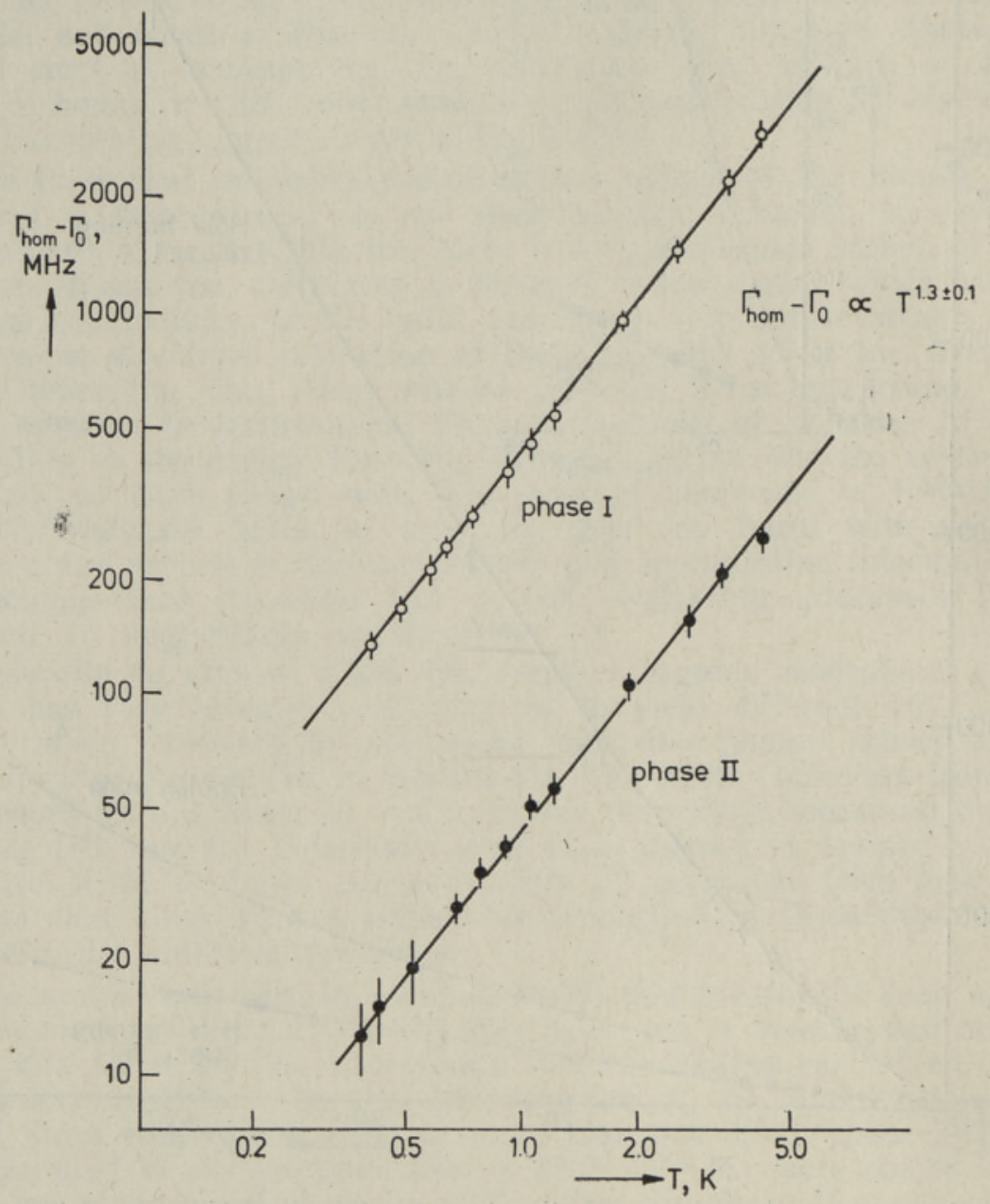

Fig. 7. Log-log plot of $\Gamma_{\text {hom }}-\Gamma_{0}$ versus $T$ for the $0-0$ transition of resorufin in phases I and II of ethanol, between $\sim 0.3$ and $4.2 \mathrm{~K}$. Both curves follow a $T^{1.3 \pm 0.1}$ dependence over at least one decade in $T\left[{ }^{4}\right]$.

Fig. 7 is a $\log$-log plot of $\Gamma_{\text {hom }}-\Gamma_{0}$ versus temperature of our holeburning data of Fig. 6. As previously found for organic glasses [ $\left.{ }^{15-20}\right]$, the curves follow a $T^{1.3}$ dependence over a temperature regime of at least one decade. From a fit of a model $\left[{ }^{24}\right]$ to our experimental results, it appears that very low frequency modes $\left(E \approx 2 \mathrm{~cm}^{-1}\right)$, in addition to twolevel-systems (TLS) (assumed to have a linear contribution in $T$, as in $\left[{ }^{24}\right]$ ), are responsible for the optical dephasing in these systems. These very low frequency modes are consistent with those previously found in our laboratory for other organic amorphous systems measured down to $0.3 \mathrm{~K}\left[{ }^{25}\right]$, but are inconsistent with a value of $E \sim 19 \mathrm{~cm}^{-1}$ deduced

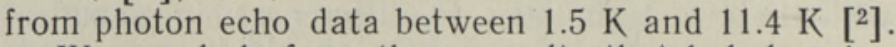

We conclude from these results that hole-burning, if properly designed, appears to be a reliable and widely applicable technique for studying optical dephasing in glasses. It has the advantage over timeresolved methods, such as photon echoes, that the samples are not required to have a good optiçal quality, and that it can be used for very short- 
lived excited states, i.e. for large values of $\Gamma_{\text {hom. }}$ Furthermore, holeburning can easily be applied to weak optical transitions, which is difficult with photon echoes.

\section{Zeeman effect in amorphous systems: free-base porphin $\left(\mathrm{H}_{2} \mathrm{P}\right)$ in polyethylene} (PE) $\left.{ }^{[}\right]$

Spectral lines of complex molecules embedded as guests in crystalline or amorphous hosts usually have inhomogeneous widths ( $\Gamma_{\text {inhom }} \simeq$ $\simeq 1-10^{2} \mathrm{~cm}^{-1} \simeq 10^{4}-10^{6} \mathrm{MHz}$ ) many orders of magnitude larger than the Zeeman shifts, or frequency shifts of electronic levels induced by a magnetic field, expected in these systems. Such small shifts cannot be detected by conventional spectroscopy, but are possible to observe with optical hole-burning because this technique allows the spectral resolution to be increased by a factor $\sim 10^{3}-10^{5}$. The narrow holes (of a few $\mathrm{MHz}$ to $\sim 1000 \mathrm{MHz}$ ) serve then as sharp frequency markers in the absorption band. Zeeman shifts of the order of some $100 \mathrm{MHz} / \mathrm{T}^{2}$ could be measured in this way in the $S_{1} \leftarrow S_{0}$ transition of $\mathrm{H}_{2} \mathrm{P}$ and chlorin incorporated in single $n$-alkane crystals at $4.2 \mathrm{~K}[6,26,27]$. When a magnetic field is applied parallel to the out-of-plane $z$-axis of the molecule, a magnetic moment is induced which mainly consists of a Van Vleck paramagnetic contribution to the frequency shift $\left[{ }^{28}\right]$. From these shifts a value of the matrix element $\Lambda=\left|\left\langle S_{1}\left|L_{z}\right| S_{2}\right\rangle\right|$ of the effective orbital angular momentum between the two lowest excited singlet states $S_{1}$ and $S_{2}$ was obtained. When the magnetic field is perpendicular to the molecular $z$-axis, no Zeeman shifts are observed.

Hole-burning has also been used to study the-Zeeman effect in various inorganic single crystals such as $\mathrm{Pr}^{3+}$ in $\mathrm{LaF}_{3}\left[{ }^{29}\right]$ and in $\mathrm{CaF}_{2}\left[{ }^{30}\right]$, and $\mathrm{Sm}^{2+}$ in $\mathrm{CaF}_{2}\left[{ }^{31}\right]$, and in the phosphorescence spectrum of coronene and 5 -bromoacenaphthene in isotropic solid solutions of ethanol and butyl bromide $\left[{ }^{32}\right]$.

Complex molecules are usually easier to incorporate in amorphous disordered materials like polymers and glasses than in ordered crystalline hosts. In this case, the molecules are randomly oriented, and the magnetic field induced shifts of the electronic levels of individual molecules give rise to a broadening, in addition to a shift, of the hole and a redistribution of its shape. We will briefly discuss here the results of such an experiment carried out in our laboratory $\left[{ }^{5}\right]$ : a magnetic field was applied on holes burnt in zero field in the $0-0$ transition of $\mathrm{H}_{2} \mathrm{P}$ incorporated in amorphous PE at $4.2 \mathrm{~K}$. The experimental results were then compared with theoretical hole shape calculations as a function of frequency and magnetic field, and the value of the magnetic susceptibility could be determined.

Holes at zero field were burnt at $\sim 6145 \AA$, and the holewidth $\Gamma_{\text {hole }}$ was adjusted by varying the burning fluence between $\sim 200 \mathrm{MHz}$ and $1000 \mathrm{MHz}$, depending on the strength of the field used to probe the hole shapes $\left[^{5}\right]$. In order to measure Zeeman shifts, two cryostats were used - one with a split-coil superconducting magnet $\left[{ }^{6}\right]$ and another as reference. Identical samples were introduced in the two cryostats at $4.2 \mathrm{~K}$, and holes were burnt in both samples at zero field. Subsequently a magnetic field (up to $7.5 \mathrm{~T}$ ) was applied to the sample in the Zeeman cryostat. The holes were probed simultaneously in both samples, before and after applying the field. In this way hole shapes and frequency shifts could be measured accurately. Examples of such experimental Zeeman shifts are shown in Fig. 8, $a$, whereas in Fig. $8, b$ we have plotted both the experimental (upside down in an enlarged scale) and the calculated hole shapes $\left[{ }^{5}\right]$. It should be noticed that the Zeeman shifts are 
a
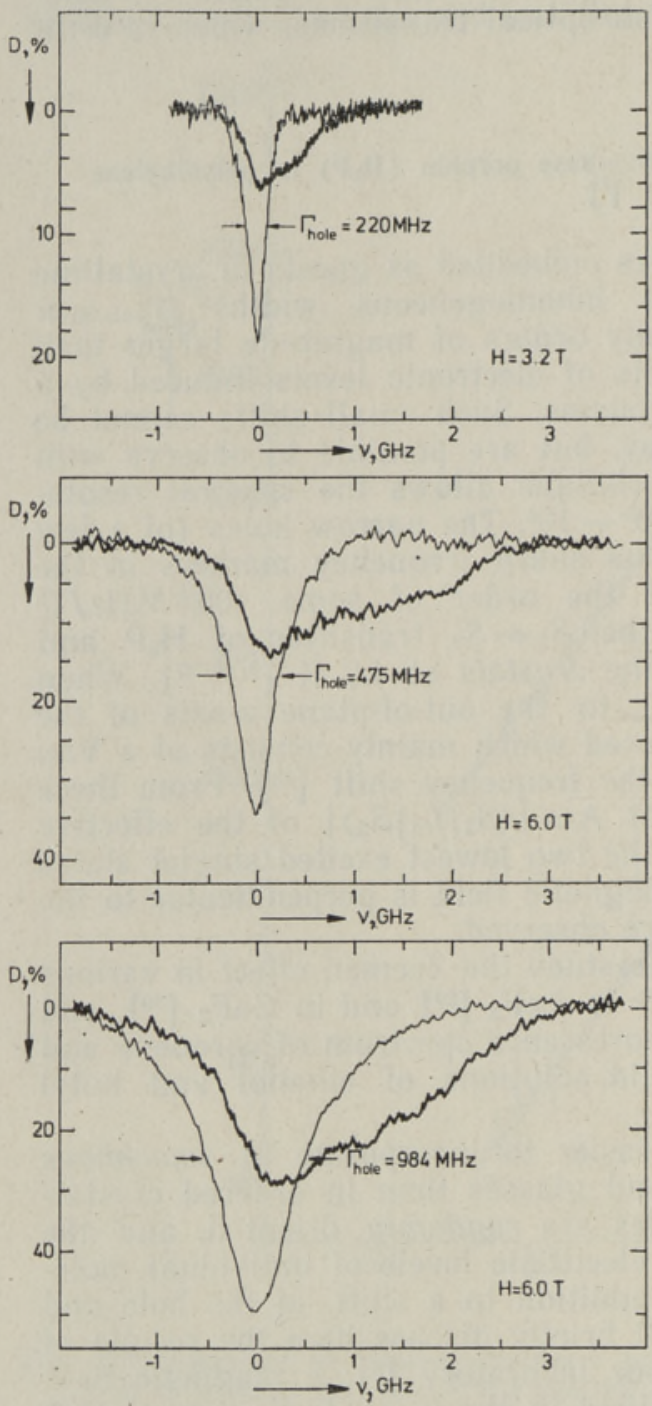

b
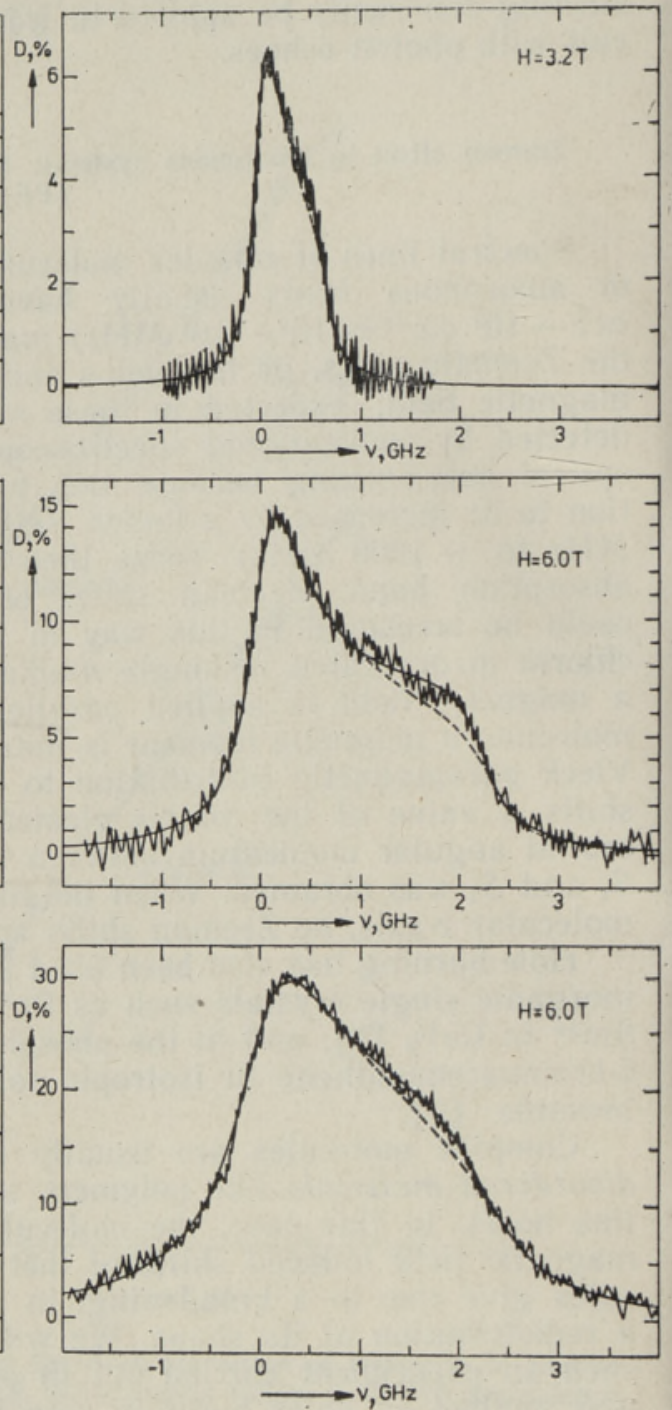

Fig. 8. $a-$ Effect of a magnetic field on holes burnt in zero field (thin curves) in the $S_{1} \leftarrow S_{0} 0-0$ transition of $\mathrm{H}_{2} \mathrm{P}$ in $\mathrm{PE}$ at $4.2 \mathrm{~K}$ for two different fields. Top: a field of $H=3.2 \mathrm{~T}$ is applied to a hole of $\Gamma_{\text {hole }}=200 \mathrm{MHz}$; middle and bottom: a field of $H=6.0 \mathrm{~T}$ is applied to holes of, respectively, $\Gamma_{\text {hole }}=475 \mathrm{MHz}$ and $984 \mathrm{MHz}$.

$b$ - Fits of the theoretically calculated hole sphapes (eqs. (1), and (2)) to the experimental results for the same three holes of Fig. $8, a$ (see text) [ $\left.{ }^{5}\right]$.

toward lower frequencies, but we have drawn them positively for convenience. Further, we have observed that the holes cycled through a magnetic field recovered their original shape and position. Reorientation of the sample did not have any effect on the hole shape, thus the sample was isotropic.

We have used two approaches to calculate the hole shape as a function of frequency and magnetic field. The first one is very simple and gives an intuitive insight into the behaviour of randomly oriented molecules in a magnetic field, but it is not completely correct. It yields, however, a good value of the magnetic susceptibility $\chi^{z^{\prime} z^{\prime}}$. The second approach 


$$
\begin{aligned}
D(v)=\text { const. } & \frac{1}{\sqrt{K H^{2}}} \times \frac{\Gamma_{\text {hole }}}{2 \pi} \int_{v}^{v+K H^{2}} \frac{1}{\sqrt{v^{\prime}-v}} \times\left\{A\left[1+\left(\frac{v^{\prime}-v}{K H^{2}}\right)^{2}\right]+\right. \\
& \left.+B\left(\frac{v^{\prime}-v}{K H^{2}}\right)\right\} \times \frac{1}{\left(v^{\prime 2}+\Gamma_{\text {hole }}^{2} / 4\right)} d v
\end{aligned}
$$

where $A=(-5 p+8), B=(18 p-16)$, and $p$ is the fraction of laser light polarized perpendicular to the field $H{ }^{[5]}$. There are now two fitting parameters, $K$ and $p$. The term in brackets represents the anisotropy created by the polarized laser light in the burning and probing processes.

The best fits to the measured hole shapes were obtained with $K=$ $=1 / 2 \chi^{z^{\prime} z^{\prime}}=61.9 \pm 1.4 \mathrm{MHz} / \mathrm{T}^{2}$ when using eq. (1) (dashed line in Fig. $8, b)$, and with $K=1 / 2 \chi^{z^{\prime} z^{\prime}}=60.6 \mathrm{MHz} / \mathrm{T}^{2}, p=0.78 \pm 0.02$ when using eq. (2) (full line in Fig. $8, b$ ). Notice in Fig. 8, $b$ that the hole shapes obtained with both eqs. (1) and (2) are very similar, although eq. (2) has a somewhat better fit. The values of $1 / 2 \chi^{z^{\prime} z^{\prime}}$, however, are identical within $2 \%$, because the magnetic susceptibility is principally determined by the cut-off tail of the curve $\left.{ }^{5}\right]$. From these fits we conclude that the values of $1 / 2 \chi^{z^{\prime} z^{\prime}}$ are in very good agreement with those previously obtained in our laboratory for the same $\mathrm{H}_{2} \mathrm{P}$ molecule in a single-crystal of $n$-octane $\left[{ }^{6}\right]$.

With these results we have demonstrated that quantitative information on magneto-optical properties of excited states of complex molecules can be extracted from disordered materials with a resolution in the $\mathrm{MHz}$ regime.

\section{Acknowledgements}

I would like to thank the organizers of the symposium on Modern Methods of Laser Spectroscopy of Molecules at Low-Temperature Media, held at the Estonian Academy of Sciences, Tallinn, USSR, May 18-22, 1987 , for bringing together such a stimulating group of international «holeburners». Further, I gratefully acknowledge the collaboration of R. van den Berg and $\mathrm{H}$. van der Laan in the work discussed here. The investigations were supported by the Netherlands Foundation for Physical Research (FOM) and Chemical Research (SON) with financial aid from the Netherland Organization for the Advancement of Pure Research (ZWO).

\section{REFERENCES}

1. Molenkamp, L. W., Wiersma, D. A. J. Chem. Phys,, 83, 1 (1985)

2. Walsh, C. A., Berg, M., Narasimhan, L. R., Fayer, M.'D. Chem. Phys. Lett., 130, 6 (1986); J. Chem. Phys., 86, 77 (1987).

3. van der Berg, R., Völker, S. Chem. Phys. Lett., 127, 525 (1986)

4. van der Berg, R., Völker, S. Chem. Phys. Lett., 137, 201 (1986).

5. van der Berg, R., van der Laan, H., Völker, S. Submitted for the Proceedings of the International Conference on Luminescence (ICL-87), Beijing, Ghina; to be submitted to Chem. Phys. Lett.

6. Dicker, A. I. M., Noort, M., Völker, S., van der Waals, J. H. Chem. Phys. Lett., 73, 1 (1980).

7. Kharlamov, B. M., Personov, R. I., Bykovskaya, L. A. Opt. Commun., 12, 191 (1974).

8. Hayes, J. M., Small, G. J. Chem. Phys., 27, 151 (1978).

9. Hayes, J. M., Stout, R. P., Small, G. J. J. Chem. Phys., 74, 4266 (1981).

10. Carter, T. P., Feary, B. L., Hayes, J. M., Small, G. J. Chem. Phys, Lett., 102,
272 (1983).

11. Jankowiak, R., Bässler, H. Chem, Phys. Lett., 95. 310 (1983). 
12. Gorokhouskii, A. A., Kaarli, R. K., Rebane, L. A. J. Exp. Theor. Phys. Lett., 20, 216 (1974); Opt. Commun., 16, 282 (1976).

13. de Vries, H., Wiersma, D. A. Phys. Rev. Lett., 36, 91 (1976),

14. Völker, S., van der Waals, J. H. Mol. Phys., 32, 1703 (1976); Völker, S., Macfarlane, R. M., Genack, A., Trommsdorff, H. P., van der Waals, J. H. J. Chem. Phys., 67, 1759 (1977).

15. Thijssen, H. P. H., Dicker, A. I. M., Völker, S. Chem. Phys. Lett., 92, 7 (1982).

16. Thijssen, H. P. H., Völker, S., Schmidt, M., Port, H. Chem. Phys. Lett., 94, 537 (1983).

17. Thijssen, H. P. H., van der Berg, R. E., Völker, S. Chem. Phys. Lett., 97, 295 (1983).

18. Thijssen, H. P. H., van der Berg, R. E., Völker, S. Chem. Phys. Lett., 103, 23 (1983).

19. Thijssen, H. P. H., Völker, S. Chem. Phys. Lett., 120, 496 (1985).

20. Thijssen, H. P. H., van der Berg, R., Völker, S. Chem. Phys. Lett., 120, 503 (1985).

21. Breinl, W., Friedrich, J., Haarer, D. J. Chem. Phys., 81, 3915 (1984).

22. Völker, S. J. Lumin., 36, 251 (1987).

23. Haida, D., Suga, H., Seki, S. J. Chem. Therm., 9, 1113 (1977).

24. Jackson, B., Silbey, R. Chem. Phys. Lett., 99, 331 (1983).

25. Thijssen, H. P. H., Völker, S. J. Chem. Phys., 85, 785 (1986)

26. Dicker, A. I. M., Noort, M., Thijssen, H. P. H., van der Waals, J. H. Chem. Phys. Lett., 78, 212 (1981).

27. Dicker, A. I. M., Dobkowski, J., Noort, M., Völker, S., van der Waals, J. H. Chem. Phys. Lett., 88, 135 (1982).

28. Canters, G. W., van der Waals, J. H. In: The Porphyrins, 3 (ed. D. Dolphin). New York, Academic Press, 1978, 531-582 and references therein.

29. Macfarlane, R. M., Shelby, R. M. Opt. Lett., 6, 96 (1981).

30. Maciarlane, R. M., Burum, D. P., Shelby, R. M. Phys. Rev., B29, 2390 (1984).

31. Macfarlane, R. M., Shelby, R. M. Opt. Lett., 9, 533 (1984).

32. Kharlamov, B. M., Al'shitz, E. I., Personov, R. I. Sov. Phys. JETP 60, 428 (1984).

33. Köhler, W., Brsinl, W., Friedrich, J. J. Phys. Chem., 89, 2473 (1985); Meixner, A. J., Renn, A., Bucher, S. E., Wild, U. P. J. Phys. Chem., 90, 6777'(1986).

Univer sity of Leiden, Netheriands

\section{AMORFSETE SUSTEEMIDE ERGASTUSSEISUNDI DUNAAMIKA UURIMINE MADALATEL TEMPERATUURIDEL SPEKTRAALSÄLKAMISE MEETODI ABIL}

On arutletud orgaanilistes amorfsetes süsteemides spektraalsälkamise ja footonkaja abil saadud optilise defaseerumise tulemuste vasturääkivuse üle. On esitatud spektraalsälkamise süstemaatilise uurimise tulemused pentatseenilisandiga PMMA ja resorufiinilisandiga etanoolklaasis temperatuurivahemikus $0,3-4,2 \mathrm{~K}$. Tulemustest järeldub, et nörgimate laserkiirguse voogudega pōletatud ja fluorestsentskiirguses mõõdetud aukude laiused peegeldavad homogeenseid joonelaiusi. On käsitletud ka spektraaldifusiooni protsesse ning demonstreeritud magnetvälja mõju amorfses süsteemis $\left(\mathrm{H}_{2}\right.$-porfiin polüetüleenis $4,2 \mathrm{~K}$ juures) nullväljas tekitatud spektraalsälkudele ja antud selle protsessi
teoreetiline interpretatsioon.

\section{Сильвия ФЕЛКЕР}

\section{ИЗУЧЕНИЕ ДИНАМИКИ ВОЗБУЖДЕННОГО СОСТОЯНИЯ В АМОРФНЫХ СИСТЕМАХ МЕТОДОМ ВЫЖИГАНИЯ ПРОВАЛА}

Обсуждаются противоречивые данные оптической дефазировки в органических аморфных системах, полученны методами выжигания провала и фотонного эха. Приведены результаты систематического изучения методом выжигання провала пентацена в полиметилметакрилате и. резөруфина в этанольном стекле в области 0,3-4,2 K, полученные в нашей лаборатории. Эти результаты показывают, что только ширины провалов, выжженных при наиболее низких потоках лазерного излучения и измеренные во флуоресценции, отражают однородные ширины линий. Обсуждаются процессы спектральной диффузии. Также показан эффект влияния магнитного поля на провалы, выжигаемые в нулевом поле в аморфных системах (безметальный порфин в полиэтилене при 4,2 K); приведена теоретическая интерпретация. 